THÉMATA. Revista de Filosofía

$\mathrm{N}^{\circ} 50$, julio-diciembre (2014) pp.: 135-150

ISSN: 0212-8365 e-ISSN: 2253-900X

doi: 10.12795/themata.2014.i50.06

\title{
EL INTELECTO HUMANO EN SPINOZA
}

\author{
SPINOZA ON HUMAN INTELLECT
}

Francisco Rodríguez Valls ${ }^{1}$
Universidad de Sevilla (España)

Recibido: 20-05-2014

Aceptado: 10-08-2014

Resumen: Las funciones del intelecto en Spinoza son la de dirigir la acción del hombre hacia una existencia plena y la de mostrar la verdad de la Naturaleza como un conjunto de relaciones necesarias. Este escrito analiza ambas funciones y se pregunta por la posibilidad de hacerlas compatibles.

Palabras-clave: intelecto, Spinoza, excelencia humana, verdades necesarias.

\begin{abstract}
Two are the goals of human intellect in Spinoza: address human action to his flourishment and explain the truth of Nature as a whole of necessary relationships. This paper analyzes these two different goals asking for their compatibility.
\end{abstract}

Key-words: intellect, Spinoza, human flourishment, necessary truths.

"Los filósofos se imaginan que cumplen una misión divina y que alcanzan la máxima sabiduría haciendo múltiples elogios de una naturaleza humana inventada para acusar de este modo más despiadadamente la que existe de hecho. No conciben a los hombres tal cual son, sino como ellos quisieran que fuesen" (B. Spinoza Tratado Político I, 1).

Las interpretaciones sobre la filosofía de Spinoza son a fecha de hoy muy diferentes de las que se hacían hace treinta años. El enfoque de entonces era especialmente metafísico y epistemológico y se ofrecía la filosofía del judío holandés desde una perspectiva de eternidad. Eso fue así hasta que comenzamos a preguntarnos por qué Spinoza daba tanta importancia a las pasiones

[1] (rvalls@us.es) Profesor Titular de Filosofía en la Universidad de Sevilla, donde se licenció con premio extraordinario y obtuvo su doctorado. Como becario de FPU realizó investigaciones postdoctorales en las universidades de Oxford, Glasgow, Viena y Munich. Entre sus libros destacan Acto y fundamento; La mirada en el espejo; Aristóteles; Hume y Antropología y utopía. En la actualidad su investigación se centra en el estudio de las estructuras emocionales de la vida humana. 
humanas y descubrimos que en ellas estaba la clave de todo: no hay perspectiva de eternidad porque para él Dios no es persona y sólo cabe el conocimiento que el intelecto finito humano haga de la realidad intentando orientarse en la marea de sus emociones y sentimientos. El ser humano es esencialmente deseo más que conocimiento. Por ese motivo no he llamado a este trabajo "El intelecto en Spinoza", sencillamente porque no hay tal cosa en su filosofía como un intelecto personal infinito. En todo caso hay "el intelecto humano en Spinoza", una capacidad que necesita un método para dirigirse adecuadamente y proporcionar un conocimiento acorde a lo real al que la especie humana tenga acceso. La necesidad de un método de la razón es herencia cartesiana que Spinoza fortalecerá a lo largo de su obra y, como todo el mundo sabe, está presente en muchos de los filósofos de la modernidad.

Spinoza concibe que el único valor seguro de la vida humana es el conocimiento. En ese sentido es muy aristotélico: todos los hombres desean por naturaleza saber. El problema es, ¿a qué costa? ¿Preferirán los hombres el saber al poder y la gloria que comporta el poder? ¿Preferirán los hombres el saber al placer? Eso constituiría todo un ámbito de discusión, pero él no entra en ello y, en el Tratado de la reforma del entendimiento, en sus primeros compases, sólo arguye su experiencia de que todos esos otros valores son fútiles y pasajeros y que, al final, lo que permanece y realmente merece la pena es la profundidad de lo que hayamos podido conocer porque eso nos pondrá en disposición de amarlo profundamente. El conocimiento nos lleva necesariamente al amor de lo conocido. Esto es importante porque muestra el objetivo de su filosofía: ¿cómo alcanzar un conocimiento verdadero que pueda proporcionar a los seres humanos una verdadera alegría fundada en un amor estable? Responder a esa pregunta es imposible en el espacio de un artículo. No obstante haré un bosquejo que ofrezca las suficientes pistas como para animar al lector a que las complete volviendo una vez más a la lectura de ese clásico que quiso pasar su existencia viviéndola anónimamente. Ese bosquejo va a consistir en los siguientes puntos: 1 . Los modos del conocimiento. Imaginación y entendimiento; 2. Cómo pasar del interior al exterior. La inmanencia del intelecto humano y su conexión con las cosas; 3. Las pasiones humanas y el conocimiento; 4. Conclusión y 5 . Referencias bibliográficas.

\section{Los modos del conocimiento. Imaginación y entendimiento}

Spinoza clasifica las diferentes formas de conocimiento que tiene el ser humano atendiendo a un espíritu común en todas sus obras. Diciéndolo desde la perspectiva del que las ha leído todas, diferencia entre el conocimiento falso -el des-conocimiento- que aporta la imaginación y el conocimiento verdadero que aporta el entendimiento. En este punto me propongo tratar con algún detenimiento esa cuestión y analizar cómo realiza esa distinción en tres de sus 
obras: Tratado sobre la reforma del entendimiento, Tratado breve y Ética. No basta una panorámica general en un estudio como éste, del que se espera cierta erudición y cierto detalle, aunque prometo no dilatarme sino ir a las cuestiones en sí mismas.

\subsection{Los modos de conocimiento en el Tratado sobre la reforma del entendimiento}

Esta obra (parágrafos 19 a 29) es el lugar donde se ofrece la clasificación más completa de los modos del conocimiento. Concretamente se enuncian en el parágrafo diecinueve y se establece que pueden ser reducidos a cuatro: las percepciones que adquirimos por el oído, las percepciones que adquirimos por experiencia vaga, percepciones en las que la esencia se concluye a partir de otra cosa y, por último, percepciones en las que una cosa es percibida por su sola esencia o por el conocimiento de su causa próxima.

La primera tiene que ver con lo que en otras obras va a llamar fe: he oído que nací tal día o que mis padres son éstos y, porque lo he oído, lo creo firmemente hasta el punto de poder decir que lo sé. Todo el mundo cree eso sencillamente porque se lo han contado y sin forma alguna de comprobarlo... entonces. Hoy sí, hoy hay registros civiles y análisis de ADN si tienes dudas, pero pocos hay que los soliciten en circunstancias poco sospechosas. Este modo de conocimiento, que según parámetros racionalistas podríamos despreciar por su debilidad intrínseca, es importante hoy en día y ha supuesto un descubrimiento por parte de la filosofía dialógica -el Yo-Tú buberiano- en el siglo XX ya que tiene como base la confianza y nos abre a mundos insospechados que no tienen que ver con el ser sino con la creación de nuevos mundos éticos, políticos y artísticos. Pero para ponerlo en valor habrá que esperar al siglo XX, en el XVII no se lo considera como conocimiento fiable.

El segundo modo se define según la "experiencia vaga". Es el conjunto de inferencias que se realizan de acuerdo con la experiencia cotidiana. Spinoza es prolijo en ejemplos: he visto morir a otros y por eso sé que moriré (entre otras cosas porque sé que soy como los otros); el aceite nutre la llama, el agua la extingue, el perro es animal que ladra y el hombre animal racional. Es la forma de conocimiento con las que obtenemos las certezas que nos permiten el vivir cotidiano o, como Spinoza lo llama, "lo habitual de la vida".

El tercer modo de conocimiento supone establecer relaciones que no vienen dadas por la experiencia directa misma: sentimos un cuerpo y de ahí concluimos que el alma está unida al cuerpo y que esta unión es la causa de tal sensación. Otro ejemplo: si conocemos la visión y observamos que cuando vemos algo de lejos nos resulta más pequeño que de cerca, de ahí podemos deducir que el Sol es más grande de lo que parece. Como puede verse, esta forma se corresponde con la argumentación y bastaría como conocimiento adecuado 
para otros tipos de filosofía. Me gustaría hacer la advertencia de que este proceso no tiene nada que ver con la abstracción clásica a partir de las cosas sensibles. Según Spinoza la abstracción no lograría darnos el carácter interno de la idea de la cosa sino solamente relaciones externas y accidentales. La argumentación concatena conceptos esenciales que no pueden establecerse de otra manera. Spinoza desprecia para el auténtico conocimiento el mundo de lo mudable y nos remite al de las ideas necesarias (cfr. parágrafos 100 y 101).

El cuarto modo se da cuando la cosa es percibida por su sola esencia. Ciertamente tiene mucho que ver con la intuición y no sólo con el hábito del tercer modo, con el que guardaría alguna relación pero con el que no coincidiría completamente. Ejemplos que ilustran esta forma: por el hecho de conocer algo sé lo que es conocer algo, por conocer la esencia del alma sé que está unida al cuerpo, dos y tres son cinco, dos líneas paralelas a una tercera son paralelas entre sí. En otro punto analizaremos los dos primeros ejemplos, pero Spinoza concluye que el problema de este tipo de conocimiento es que las cosas que ha podido conocer a través de él son muy pocas.

Spinoza descalifica los dos primeros modos de conocimiento precisamente porque no nos hacen conocer las esencias de las cosas. A través de ellos sólo podemos obtener experiencias singulares y accidentes. Los que se presentan como auténticos candidatos al modo ideal de conocimiento son el tercero y el cuarto y entre ellos habrá que decidir. Spinoza justifica su elección con un ejemplo matemático: la proporcionalidad de los números. Según el tercero, a partir de la experiencia de cosas simples se deduce (no se abstrae en el sentido clásico del término) un axioma universal. Según el cuarto la proporcionalidad se establecería de forma intuitiva por el propio concepto de proporcionalidad. Todo eso es un problema al que prestaremos atención un poco más adelante, pero no hay duda de que si eso es así, el modo preferible de conocimiento es el cuarto ya que nos pone directamente en contacto con las esencias mismas de las cosas y eso, a ojos de buen racionalista, supone el cumplimiento máximo del conocimiento.

\subsection{Los modos de conocimiento en el Tratado breve}

En el Tratado breve (II, 1 y 2) los cuatro modos de la obra anterior se reducen a tres: por simple fe surgida de la experiencia o de oídas, por fe verdadera y, en tercer lugar, por comprensión clara y distinta. En este caso la dificultad es más terminológica que otra cosa porque, como veremos, en esencia se ajusta a lo que se sostiene en el Tratado sobre la reforma del entendimiento. Sobre todo, el problema se atiene al uso que hace del término fe aplicado al primer y segundo modo y que podríamos explicar diciendo que todo conocimiento por fe se limita a hacer caso de la autoridad de otro: ya sea a quien te dice el día de tu nacimiento, ya sea la experiencia cotidiana que 
suponemos que seguirá siendo siempre la misma (perdón porque esto suene demasiado a Hume) o el hecho de deducir conclusiones generales de conceptos desde casos particulares en cuyo caso nos sometemos a la autoridad de la razón. En este sentido podemos decir que Spinoza reduce a uno los dos primeros modos del Tratado sobre la reforma del entendimiento, llama fe verdadera al tercer modo y define en los mismos términos conceptuales el cuarto modo que aquí convierte en tercero.

Tal y como lo hemos planteado conscientemente, no cabe duda que el primer modo es una fe. ¿Pero qué quiere decir nuestro autor cuando al conocimiento de la razón lo llama "fe verdadera"? Sencillamente lo que demuestra es que el ser humano deposita enteramente su confianza en la razón y a ella asiente. En lugar de asentir a una subjetividad lo hace a la facultad de razonar. El último modo no necesita, frente a éste, argumentación sino que ve en sí la cosa misma.

Para explicar los tres modos de conocimiento acude al mismo ejemplo de la proporcionalidad de los números que puso en la obra que analizamos anteriormente. Como el subpunto pasado era más extenso que este expuse el ejemplo sin detenimiento. Permítaseme ahora que abunde un poco más en él en aras de una mejor comprensión de los conceptos. Spinoza explica las diferentes formas de adherirse a la verdad de la proporcionalidad de los números concretándola en la aplicación de la regla de tres: a uno le han contado que si uno multiplica el segundo número por el tercero y después lo divide por el primero encuentra un cuarto número que tiene con el tercero la misma proporción que el segundo con el primero, eso lo aplica, le funciona y con eso basta; un segundo (la fe por experiencia) prueba algunos casos particulares y, al ver que resultan, confía plenamente en el argumento y lo sigue aplicando sin más consideración²; en un tercer caso el ser humano consulta a su razón y ésta, bien utilizada, le da la certeza de la verdad; el cuarto caso, que se corresponde con el tercer modo de conocimiento, "ve al instante, con su intuición, la proporcionalidad y todos los cálculos". Dejaríamos la argumentación ahí si Spinoza no enunciara un poco más adelante algo que nos servirá para comprender mejor su intención global con respecto a la naturaleza humana. Espero que citarlo en este momento no resulte demasiado misterioso ya que intentamos dejar claro desde el principio que nuestro tema no se detiene en teoría del conocimiento sino que pretendemos hablar del alma humana. Dice así nuestro autor: "Llamamos conocimiento claro a aquel que no se adquiere mediante convicciones de la razón, sino mediante un sentimiento y un gozo de la cosa misma, y supera con mucho a los demás" (II, 2, 2).

[2] Este sería el ámbito propio donde se plantea el problema de la inducción en Spinoza. La diferencia con la filosofía empirista radicaría en introducir el problema mismo dentro de la razón y convertir lo que Spinoza llama aquí "fe verdadera" en una "creencia racional".

THÉMATA. Revista de Filosofía, №50 julio-diciembre (2014) pp.: 135-150 doi: 10.12795/themata.2014.i50.06 


\subsection{Los modos de conocimiento en la Ética}

En la Ética demostrada según el orden geométrico es donde, a mi parecer, encontramos la división más madura de los modos de conocimiento. Se encuentra en el escolio segundo de la proposición cuarenta de la segunda parte. Al igual que en el Tratado breve establecerá tres géneros de conocimiento pero la precisión con que lo hace es mayor y atiende más a lo esencial que se requiere en gnoseología. Por poner un ejemplo, en su obra de madurez abandona la terminología del conocimiento por fe y la sustituye por la de "opinión" y la de "imaginación" que constituirán el primer género de conocimiento. Este género en su diferencia con los demás es esencial para comprender la filosofía de Spinoza ya que no marca distancias con cualquier conocimiento obtenido por la experiencia y va a generar problemas importantes a los que el autor holandés tendrá que dedicar mucho espacio para obtener soluciones poco satisfactorias.

Según Spinoza al primer género de conocimiento corresponden dos formas: primero "a partir de las cosas singulares, que nos son representadas por medio de los sentidos, de un modo mutilado, confuso y sin orden respecto del entendimiento" 3 ; segundo "a partir de signos; por ejemplo, de que al oír o leer ciertas palabras nos acordamos de las cosas, y formamos ciertas ideas semejantes a ellas, por medio de las cuales imaginamos esas cosas". Sobre esta cuestión podríamos extendernos, pero creo que será mejor dejar la discusión para más adelante y caracterizar este modo de conocimiento como "externo" a las cosas mismas ya que consistiría en agrupaciones que los sentidos realizan de pluralidades desordenadas de sensaciones frente a las que el conocimiento intenta poner cierto orden. El postulado que establece Spinoza es que desde este conocimiento "externo" nunca podremos llegar a la esencia misma de las cosas.

El segundo género, la "razón", sería aquel por el que "tenemos nociones comunes e ideas adecuadas de las propiedades de las cosas". El problema es que no se arguye cómo se tienen: ¿innatamente?, ¿a través de una argumentación que nos haga conectar internamente con las cosas mismas? Si es así, ¿cómo demostrar la connaturalidad entre sujeto y objeto?

"Además de estos dos géneros de conocimiento, hay un tercero, al que llamaremos "ciencia intuitiva". Y este género de conocimiento progresa, a partir de la idea adecuada de la esencia formal de ciertos atributos de Dios, hacia el conocimiento adecuado de la esencia de las cosas". Ciertamente oscuro el enunciado de este tercer género, máxime cuando intenta explicar los tres géneros de conocimiento con el mismo ejemplo que en las otras dos obras: unos

[3] Dice Spinoza que a ese conocimiento lo va a llamar "experiencia vaga". La pregunta que me gustaría realizar es: ¿en qué medida toda experiencia no caería bajo esta acepción? Según la respuesta que se dé a dicha pregunta se marcarían unas diferencias u otras con respecto al empirismo.

THÉMATA. Revista de Filosofía, №50 julio-diciembre (2014) pp.: 135-150 doi: 10.12795/themata.2014.i50.06 
creen en la regla de tres, otros argumentan la regla de tres, otros intuyen la verdad de la regla de tres sin mediación de la razón. La conclusión a la que Spinoza llega al respecto es que el primer género es causa de la falsedad mientras que los otros dos son verdaderos necesariamente aunque es, sin duda, al tercero al que debe considerarse más perfecto.

Lo que nos debe quedar claro, digamos esto como conclusión de este punto, es que una cosa es la imaginación y otra el conocimiento. Imaginar es fácil, conocer no. Para imaginar basta conectar estímulos externos y, si además se hace de forma original, mejor. Para conocer hace falta mancharse con la esencia de las cosas y abandonar el capricho de la propia subjetividad. Pero eso precisamente constituye el problema básico de la cuestión: ¿cuándo las imágenes de las cosas pasan de ser sólo imágenes fingidas a ser esencia de las cosas? Si se quiere: ¿cómo pasar del subjetivismo a la subjetividad que conecta con el objeto? No es poca cosa esa pregunta si con ella nos jugamos la plenitud del hombre.

\section{Cómo pasar del interior al exterior. La inmanencia del inte- lecto humano y su conexión con las cosas}

Uno de los graves problemas que se plantea al conocimiento cuando lo enfocamos desde el racionalismo es cómo la subjetividad inmanente puede dar cuenta del mundo trascendente: cómo acceder al exterior desde el interior. ¿Cómo captar la esencia de las cosas con las facultades intelectivas? Para ello, si no basta la experiencia externa, tendrá que haber una aprehensión directa de la esencia. Si lo vemos bien eso significaría, en el mejor de los casos, rescatar a la ontología desde la gnoseología y nos lleva a la cuestión del acceso al ser. En el peor de los casos todo quedaría reducido a pura inmanencia y sería difícil distinguir realidad de sueño de la razón. Los seres humanos obran y plantean sus vidas de acuerdo con los modos de conocimiento que vimos en el punto anterior. El problema es que unos nos ofrecen un auténtico sentido de realidad y otros no. La imaginación y la opinión no lo ofrecen y, consecuentemente, el hombre que se rija por ellas no tendrá plenitud en su vida. Sólo tener ideas adecuadas de las cosas nos ofrece el sustento suficiente como para cumplir satisfactoriamente un destino. La descripción de Spinoza es perfecta en teoría: sólo la razón y la ciencia intuitiva son auténtico conocimiento. Pero eso no soluciona el problema de cómo llegar a él porque el hombre contingente tiene que orientarse sólo a través de percepciones confusas y mutiladas que le vienen del exterior y que unifica como puede hasta formar hipótesis sobre los objetos. La pregunta sería: ¿cómo salir del círculo de la contingencia, de la opinión, para alcanzar un conocimiento adecuado? El hombre contingente del que hemos hablado es el que considera el empirismo y el que lleva al escepticismo de Hume. Sin embargo, Spinoza no es un escéptico, ¿cómo justifica que el ser 
humano pueda hallar un conocimiento adecuado? Eso nos remite precisamente a la función que desempeña el intelecto en la vida humana y cómo conociendo el orden del mundo el ser humano estará llamado a amarlo.

Para dar razón de lo anterior, si es cierto que ninguna experiencia externa nos lleva a la esencia, sólo cabe postular que el entendimiento humano refleja en sí el orden del mundo y puede explicitarlo a través del ejercicio de su propia capacidad. Pero para ello requiere un método que dirija bien su actividad y la haga alcanzar la verdad necesaria. Es cierto que tanto en la Ética como en el Tratado breve la idea de método está prácticamente ausente y en ellas ya se nos presenta el sistema realizado de acuerdo con él. En el Tratado de la reforma del entendimiento, sin embargo, la idea de hallar el método adecuado está consciente y temáticamente tratada y, además, con algunos términos de clara reminiscencia cartesiana. El Tratado de la reforma del entendimiento cumple en Spinoza una función similar a la que el Discurso del método cumple en Descartes. Voy a centrarme preferentemente en él para justificar mi argumentación a la vez que pasamos revista al resto de las obras.

En el parágrafo 36 de la obra a la que me refiero dice Spinoza: "el verdadero método es el camino por el cual la verdad misma, o las esencias objetivas de las cosas, o las ideas (todo esto significa lo mismo), son buscadas en el orden debido". Esa cita nos da el fin al que tiende el intelecto, la búsqueda de la verdad que es idéntica a esencia objetiva o idea de la cosa. Si seguimos ese método seremos capaces, ese es su fin, de "conocer qué es la idea verdadera distinguiéndola de las demás percepciones” (parágrafo 37). Pero, he aquí una pregunta clave, ¿cómo distinguir la verdad de lo que no es más que figuración? Para ello el ser humano debe proceder poco a poco, con instrumentos conceptuales muy simples e ir ascendiendo lentamente en complejidad. Si se sigue este paciente método no habrá forma de confundir una cosa con otra porque la verdad "se hace de por sí evidente" (parágrafo 44). En la Ética es igual de claro al afirmar, en la proposición cuarenta y tres de la parte segunda, que "quien tiene una idea verdadera, sabe al mismo tiempo que tiene una idea verdadera, y no puede dudar de la verdad de eso que conoce". Y en el escolio de esa proposición, para evitar cualquier tipo de duda, afirma taxativamente lo que sigue: "cómo puede un hombre conocer que tiene una idea que se adecúa a aquello de lo que es idea, acabo de mostrar más que suficientemente que ello surge del solo hecho de que efectivamente la tiene, o sea, surge de que la verdad es norma de sí misma". La tesis es clara, de eso no hay duda, pero es problemática y hay que explicarla para distinguir entre lo que podríamos llamar "creer" que se tiene una idea adecuada y "saber" que se tiene una idea adecuada. Subjetivamente puede haber confusión entre ambas situaciones objetivas y es imprescindible despejar la incógnita.

Despejar la incógnita significa hacer ver que el conocimiento humano debe proceder desde lo más simple a lo más complejo, tiene que partir de lo 
claro y distinto y construir sobre ello progresivamente hasta alcanzar la verdad sobre la totalidad del universo. Ciertamente, en esta idea, Spinoza asume las reglas cartesianas contenidas en la segunda parte del Discurso del método. Cualquiera que leyera en el siglo XVII el Tratado sobre la reforma del entendimiento necesariamente sabría a quién está acudiendo Spinoza para resolver el problema de la verdad y del criterio de verdad. Veamos algunos textos que lo dejan meridianamente claro: "por lo tanto, de ninguna manera deberemos temer figurarnos algo si percibimos la cosa clara y distintamente" (parágrafo 62); "además, basta con que la primera idea no sea figurada y que todas las demás sean deducidas de ella para que la tendencia a figurarse algo se desvanezca poco a poco", "si una idea es la de una cosa muy simple, no podrá ser sino clara y distinta" (parágrafo 63); "si la cosa que está compuesta por muchas es dividida por el pensamiento en todas sus partes más simples y se presta atención a cada una por separado, toda confusión desaparece" (parágrafo 64); "las ideas que son claras y distintas nunca pueden ser falsas: pues las ideas de las cosas que son concebidas clara y distintamente son o bien simplicísimas o bien compuestas de ideas simplicísimas, es decir, deducidas de ideas simplicísimas" (parágrafo 68). El fundamento de la verdad en todo el racionalismo depende en consecuencia de este tipo de atomismo que hace que el criterio de verdad sea indiscutiblemente la certeza, una certeza que no es sino el asentimiento a la evidencia de contemplar lo simple en sí mismo y de elaborar lo complejo a partir de lo simple con la meticulosidad suficiente como para no omitir nada ni suponer nada. Si eso es así, no es extraño que el orden racionalista deba ser geométrico, matemático en general o lógico-matemático en particular (como el ars combinatoria de Leibniz). Y ello nos explica también que para conocer la realidad no tengamos que acudir a nada extramental en tanto que el intelecto se basta a sí mismo para dar cuenta de la realidad completa: "El objetivo, pues, es tener ideas claras y distintas, es decir, ideas tales que sólo sean producidas por el Alma y no por movimientos fortuitos del cuerpo. Después, para reducir todas las ideas a una sola, trataremos de concatenarlas y de ordenarlas de tal modo que nuestra Alma, por cuanto le es posible, reproduzca objetivamente la formalidad de la naturaleza, tanto en su totalidad cuanto en sus partes" (parágrafo 91). No hay exterior ni interior, la totalidad es una inmanencia en la que cada cosa está conectada con las demás y el instrumento adecuado para dar cuenta de ese orden interno de todo con todo es el intelecto.

Con lo dicho creo que estamos ya en situación de dar cuenta del intelecto, de ese instrumento que es capaz de producir y componer las ideas de las esencias objetivas de las cosas. Spinoza estudia sus propiedades en el parágrafo 108 de su Tratado sobre la reforma del entendimiento. Analiza exactamente ocho propiedades de las que aquí señalaremos seis ya que la séptima y la octava no hacen referencia directamente al intelecto sino que la séptima se refiere a las operaciones que el alma realiza con los conceptos del intelecto 
y la octava a la mayor perfección de la idea mientras mayor sea la perfección del objeto. En primer lugar, el intelecto "envuelve certeza, es decir, sabe que las cosas son formalmente como están contenidas en él objetivamente". En segundo lugar, produce ideas y compone unas ideas a partir de otras. En tercer lugar, "las ideas que forma de manera absoluta expresan una infinidad". En cuarto lugar, forma sobre todo ideas positivas y, en quinto, "percibe las cosas no tanto sujetas a la duración, sino más bien como cierta perspectiva de eternidad y en número infinito". En sexto, "las ideas claras y distintas que formamos se siguen sólo de la necesidad de nuestra naturaleza". Creo que adentrarse en el significado de estas propiedades facilita mucho la comprensión de las otras obras de Spinoza, especialmente de la Ética, pero la visión del intelecto que se nos ofrece aquí es todavía parcial y no recoge todos los aspectos en los que Spinoza quiere profundizar. La visión del intelecto que ofrece el Tratado de la reforma del entendimiento acaba en concebirlo sub specie aeternitatis. Pero ya dijimos al comienzo que ese tipo de interpretaciones que acaban en "cómo debe ser" el entendimiento están desfasadas. Tenemos que acudir a cómo funciona de hecho y, en consecuencia, superar el intelectualismo radical en una visión que contemple el intelecto humano en su bregar cotidiano con la realidad.

\section{Las pasiones humanas y el conocimiento}

Parafraseando algunas expresiones de la Ética, el hombre no es imperio dentro de un imperio sino que se ve afectado por una multitud ingente de seres con los que entra en relaciones voluntarias e involuntarias, esenciales y accidentales, así como él afecta a muchos otros con los que se relaciona de igual forma. Su pequeñez es incomparable con la infinitud del cosmos por lo que una imagen que reflejaría bien su condición es la de un barco que se debate por mantenerse a flote entre grandes tempestades. Orientar su acción es lo que busca para llevar una vida plena y no ser destruido por los vaivenes de deseos contrarios. El ser humano necesita guías seguras y necesita orientarse en el torbellino de las sensaciones. Es por ello por lo que el conocimiento le es útil para ese propósito: hacerse una idea cabal de sí mismo y del mundo lleva a adquirir criterios seguros sobre lo que es importante y lo que no, sobre lo que hay que hacer y lo que no compensa hacer. La esencia del hombre consiste en deseo, deseo de conservar su ser y deseo de perfeccionarlo hasta el extremo. El problema es qué se entiende por perfección humana porque eso, a priori, el ser humano no lo sabe y es un ser complejo que se ve atraído por múltiples impulsos. Ese deseo de acción virtuosa, de plenitud humana, debe ser normativizado conforme a un plan, una imagen de la naturaleza humana que dirija nuestra acción y permita orientarnos frente a la pluralidad de impulsos encontrados que nos motivan a hacer en tiempos diversos unas cosas y sus contrarias. El ser humano necesita orientación y, para ello, la mejor guía es dirigir la propia 
vida a la obtención del conocimiento. Es la mejor estrategia para completar una vida dichosa que esté por encima de la contingencia del tiempo.

Spinoza dedica mucho espacio, especialmente en su Ética pero también en el Tratado breve, a hablar de las pasiones. Aunque sólo sea por criterios cuantitativos y externos hay que concebir que esa temática le es esencial para comprender la naturaleza humana. Realmente no es otra cosa más que el punto de partida: la confusión y la precariedad humana que necesita desesperadamente una guía segura. En el tratamiento de la dinámica de las pasiones encontramos análisis finísimos que justifican la fama de maestro y de sabio que tuvo Spinoza. También en los análisis particulares de cada pasión encontramos justificadamente que es un excelente conocedor del ser humano.

$\mathrm{Al}$ ser humano, como a cada ente del universo, le es aplicable que se esfuerza todo lo que puede por permanecer en su ser. Esta ley del conatus, que Spinoza enuncia y desarrolla a partir de la proposición sexta de la tercera parte de la Ética, coincide con la noción de apetito y en el ser humano se eleva hasta la noción de "deseo" siendo el deseo "el apetito acompañado de la conciencia del mismo" (Ética III, 9, escolio). El hombre quiere permanecer en su ser y siente alegría cuando su esfuerzo le hace consciente de que lo logra y de que aumenta su perfección y siente tristeza cuando es consciente de que su esfuerzo no lo consigue y de que, en consecuencia, su perfección decae. Pues bien, según Spinoza, deseo, alegría y tristeza son los tres afectos primarios y todos los demás surgen de ellos (cfr. Ética III, 11, escolio). No voy a entrar en detallar la génesis de los afectos, baste decir que esos tres son suficientes para comprender que el hombre busque, "imagine" dice Spinoza, cómo perfeccionarse y aumentar su alegría y cómo evitar fracasar y eludir la tristeza. Pero esa búsqueda no es fácil ya que el hombre debe fabricar un modelo de su propia excelencia y los objetos que se le presentan como supremos son múltiples. Al comienzo del Tratado sobre la reforma del entendimiento, en el parágrafo tres, deja bien claros los tres bienes que al ser humano se le presentan como máximos: la riqueza, el honor y la libido. No lo tiene nada fácil el ser humano para formarse una idea de perfección ante tantos y poderosos candidatos. Habría que ser muy prolijo para desestimar algún pretendiente a excelencia, pero Spinoza despacha rápidamente la cuestión acudiendo a la "experiencia" de que ni la riqueza, ni el honor, ni el placer pueden llenar el corazón del hombre. Tan sólo Dios puede hacerlo, pero no el Dios de la religión porque es difícil en la religión separar lo esencial de la superstición, sino el amor a Dios que se deriva del conocimiento de la naturaleza entera: conocer las esencias de las cosas implica amarlas y conocer adecuadamente la naturaleza lleva necesariamente al amor a Dios y el hombre que ama con un amor fundado en el conocimiento es un hombre pleno.

No sé si al lector le convencerá el argumento de que el hombre sabe por "experiencia" que sólo el conocimiento le puede llevar a la plenitud. Desde luego no es una experiencia sociológicamente mayoritaria, pero eso también

THÉMATA. Revista de Filosofía, №50 julio-diciembre (2014) pp.: 135-150 doi: 10.12795/themata.2014.150.06 
explicaría por qué nuestra sociedad opulenta es a la vez una sociedad insatisfecha. Aunque no entre en razones sino que dé por supuesta la estabilidad del ánimo como un valor necesario derivado de su visión intelectualista, no por eso deja de hacer mención alguna vez -encuentro en ello una cierta ironía- de que "tampoco hay pequeña distancia entre el gozo que domina a un ebrio y el gozo de que es dueño el filósofo" (Ética III, 57, escolio). Habría que analizar más detenidamente la cuestión y formular una noción consistente de virtud y de felicidad en esta línea, tal como hace Aristóteles en la Ética a Nicómaco, pero eso excede los propósitos de este artículo: tendremos que contentarnos con la opinión y con la experiencia de Spinoza.

El candidato que propone Spinoza para evitar la fluctuación del ánimo y alcanzar una vida plena es una acción guiada por el conocimiento. Ahora bien, es experiencia común que el conocimiento no basta para cumplir los objetivos. El adagio "sé lo que es bueno, hago lo que es malo" habla por sí mismo de que el saber teórico no impide el fracaso humano. Al menos Spinoza no cae en la trampa de una versión ingenua del intelectualismo moral aunque de hecho pueda caer en otras más elaboradas. En este sentido hay un texto del Tratado breve (II, 22, 1) que es necesario considerar porque muestra una afirmación que después no va a aparecer en la Ética: "Dado que la razón no tiene poder para conducirnos a la felicidad, no nos queda sino investigar si podemos alcanzarla mediante la cuarta y última forma de conocimiento". Esas líneas llevarían a desarrollar una idea de ciencia -en tanto que conocimiento teórico acerca de la totalidad de la naturaleza- distinta a la de sabiduría como conocimiento práctico que guía al hombre a la salvación. El tercer género de conocimiento nos llevaría a la ciencia y el cuarto a la sabiduría. El científico podría ser malo a pesar de su conocimiento, sólo el sabio podría ser considerado como hombre santo. Pero esa interpretación dista mucho de lo que se sostiene en la Ética ya que en ella la salvación se obtiene precisamente a través de la adquisición del conocimiento de la totalidad en la cual se aprecia la necesidad que rige la totalidad misma: la salvación se obtiene por el conocimiento. En cualquier caso, cualquier conocimiento no nos hace dueños de nosotros mismos ni nos libra de los movimientos de las pasiones.

¿Tiene el ser humano alguna forma de conseguir una estabilidad en su espíritu que le permita hacer lo que sabe que es bueno? Spinoza habla de forma crítica de la visión que tanto los estoicos como Descartes tienen y en la que, según ellos, el ser humano podrá someter las pasiones a la razón. Pero aunque no concuerde plenamente con sus razones sí admite una vía por la que es posible. Esa vía consiste sobre todo en una visión intelectualista de la vida práctica según la cual las acciones deben de realizarse según el punto de vista de la eternidad. Digo visión intelectualista porque ya dejamos claro en el segundo punto que, precisamente, una de las propiedades del intelecto, concretamente la quinta, era la superación del tiempo. Esto, que tan raro resulta después de 
Heidegger, es una condición básica para entender el espíritu del racionalismo de Spinoza: la verdad es inmutable y nada hay que sea contingente. También el ser humano es un ser natural que no admite hermenéuticas diferentes para cada individuo. El tiempo no añade nada a la esencia de las cosas, formamos un entramado de relaciones que sin problema alguno podría considerarse en un eterno presente en el cual los entes estuvieran ordenados por sus relaciones causales. Contemplar esa escena nos libera de conceptos subjetivos como los de bien y mal y libertad como indeterminación y hacen entrar al hombre en una dimensión nueva, en un "renacimiento" como lo llama en el Tratado breve, en el que ama el orden infinito de la totalidad infinita.

¿Cómo se consigue entrar en la perspectiva de Dios? Realmente me gustaría saberlo, mucho más cuando Spinoza lo hace depender de uno mismo al no dar cabida a revelación alguna por parte de un Dios personal. Pero después de darle muchas vueltas a la Ética y de atender a la conexión entrañable que guardan en ella el segundo y el tercer género de conocimiento me queda una esperanza que me transmite la proposición veinticuatro de su quinta parte: "cuanto más conocemos las cosas singulares, tanto más conocemos a Dios". De alguna forma la imagen del universo que nos vamos formando con el segundo género de conocimiento nos llevará al tercero: nos hará intuir las cosas en su totalidad y de ahí nacerá el gozo por el que se caracteriza el conocimiento claro según vimos en el primer punto. Sé que mi interpretación es discutible porque el hábito del segundo género de conocimiento es cualitativamente distinto de la intuición pura que implica el tercero, pero, además de que hay algunos textos que podrían ser interpretados en ese sentido, no me resigno personalmente a perder la esperanza de ser sabio algún día si ser sabio significa lo que Spinoza nos transmite con las palabras con las que concluye su Ética y que parecen indicar una ascética que estoy dispuesto a emprender: "El sabio, considerado en cuanto tal, apenas experimenta conmociones de ánimo, sino que, consciente de sí mismo, de Dios y de las cosas con arreglo a una cierta necesidad eterna, nunca deja de ser, sino que siempre posee el verdadero contento de ánimo. Si la vía que, según he mostrado, conduce a ese logro parece muy ardua, es posible hallarla, sin embargo. Y arduo, ciertamente, debe ser lo que tan raramente se encuentra. En efecto: si la salvación estuviera al alcance de la mano y pudiera conseguirse sin gran trabajo, ¿cómo podría suceder que casi todos la desdeñen? Pero todo lo excelso es tan difícil como raro".

\section{Conclusión}

Estamos tan acostumbrados a las éticas mínimas que nos llevan a vivir cómodamente salvaguardando las apariencias del derecho que cuando se presenta una ética de la excelencia prácticamente la rechazamos como si estuviera hecha sólo para unos pocos y, en consecuencia, no nos afectara. Pues bien, la 
ética de Spinoza pretende ser una ética de la excelencia que se funda en la idea del sabio y requiere toda una teoría del conocimiento y toda una metafísica que la justifique. Este trabajo ha pretendido conjugar esos tres aspectos dando prioridad al enfoque epistemológico ya que su objeto principal era el estudio de qué entiende Spinoza por intelecto. Creo que habrá llamado la atención de los que conocen bien la epistemología clásica que Spinoza no haga un análisis de las facultades en aras de proceder a cómo se obtiene el concepto y la verdad. Para un racionalista esa imagen no es posible ya que el proceso de abstracción no puede dar nunca como resultado la aprehensión de la esencia interna de las cosas. En ese sentido, Spinoza no requiere ningún entendimiento agente que ilumine para sacar las formas de los particulares. Spinoza es muy diferente de Aristóteles, prácticamente es su reverso, y de ahí sus críticas a la causa final, a la doctrina de la definición por género y diferencia específica, a la demostración que va de los efectos a las causas, etc. El sistema spinozista es el gran sistema de la inmanencia, el gran sistema que admite una sola sustancia en la que todo está conectado con todo por razones absolutamente necesarias.

Si lo anterior es así, el sistema del conocimiento y la función del intelecto es la de desplegar internamente la totalidad de esas razones necesarias. Por ello el mejor sistema para explicarlo es un sistema geométrico que no requiere para su exposición más que partir de un conjunto de axiomas y de principios desde donde todo lo demás se desplegara de forma inmanente y necesaria.

Lo anterior está justificado desde el punto de vista del sabio y esa sería la función del intelecto en sí mismo considerado y ya está. A ese sistema sólo le faltaría ser consciente para ser un Dios personal. Pero Spinoza no le atribuye consciencia a la substancia sino sólo a los seres humanos, son los seres humanos los que tienen un intelecto personal que debido a su contingencia debe ser bien dirigido por un método riguroso que tenga a la certeza como piedra de toque. Ya vimos lo mucho que debía Spinoza a Descartes en esa función, pero Spinoza ataja sus problemas en temas fundamentales, como la unión entre cuerpo y alma a través de la doctrina de los atributos o el origen de nuestras ideas innatas (que no pueden ser "puestas" por Dios en nuestro intelecto) sino que naturalmente forman parte de él, de una forma que creo más solvente que las del filósofo francés. En cualquier caso, la función principal del intelecto, y con ello entro en las interpretaciones más recientes de Spinoza, es la de dar una orientación a la vida de los seres humanos que es sumamente necesitada. Si la naturaleza del hombre es deseo, el intelecto le enseña a dirigir su deseo hacia los ideales que conciba como más excelsos. De esa manera el hombre encontrará la paz y el descanso del corazón. ¿No es acaso eso lo que pretenden los seres humanos cuando afirman que quieren ser felices?

Efectivamente hay un problema serio a la hora de articular ambas funciones del intelecto porque parece que la dirección del intelecto admite la posibilidad del error y eso explica que deba ser dirigido y, en consecuencia, 
requiere la libertad y tratar sobre el bien y el mal, la virtud y el vicio, el mérito y el demérito, etc., conceptos que desde el punto de vista del sabio no tienen sentido alguno. El problema que Spinoza no plantea, quizás porque no merezca la pena ser planteado aunque personalmente me hubiera gustado mucho que lo hiciera, es que si todo es necesario cuál es la función de la ética, del derecho, del esfuerzo y, para establecerlo en términos cognoscitivos, del aprendizaje en general. El intelecto sabe pero el saber no importa en último término porque no tiene ninguna influencia causal sobre la realidad en ningún sentido: por eso no hace falta que Dios tenga conciencia. La imagen que queda es la del espectador, la del puro espectador, y esa me resulta claramente insuficiente para un mundo que pide a gritos la acción y la colaboración. Se podría objetar a mi crítica diciendo que qué le importa al universo la situación de seres menesterosos destinados a perderse en la nada. Pero eso implicaría un debate no ya sobre el intelecto humano sino sobre el intelecto divino, sobre Dios en general, y sobre el sentido del Universo en el que Spinoza y el que suscribe mantenemos tesis muy diferentes que sobrepasan los límites de este ensayo. 


\section{Referencias bibliográficas:}

La consulta de las obras de Spinoza se ha realizado por la siguiente edición:

Spinoza Opera herausgegeben von Carl Gebhardt. Heidelberg. Carl Winter, 1921.

Las citas de las obras de Spinoza en el artículo se han hecho por las siguientes traducciones:

Spinoza, B. Tratado teológico-político. Tratado político. Madrid. Tecnos, 1966. Traducción y estudio preliminar de Enrique Tierno Galván.

Spinoza, B. Ética. Madrid. Alianza editorial, 1987. Introducción, traducción y notas de Vidal Peña.

Spinoza, B. Tratado de la reforma del entendimiento y otros escritos. Madrid. Técnos, 1989. Estudio preliminar, traducción y notas de Lelio Fernández y Jean Paul Margot.

Spinoza, B. Tratado breve. Madrid. Alianza editorial, 1990. Introducción, traducción y notas de Atilano Domínguez.

Entre la inabarcable bibliografía existente sobre Spinoza algunos estudios de interés que considero que sirven para completar y profundizar en la temática tratada son los siguientes:

Alquie, F. Le rationalisme de Spinoza. Paris. PUF, 1981.

Bennet, J. A study of Spinoza's Ethics. Cambridge. Cambridge University Press, 1984.

De Deugd, C. The significance of Spinoza's first kind of knowledge. Assen. Van Gorcum, 1966.

Deleuze, G. Spinoza. Paris. PUF, 1970.

Lermond, L. The form of man. Human essence in Spinoza's Ethics. Leiden. Brill, 1988.

Rodríguez Valls, F. "Ser y conocimiento en la Ethica de Spinoza", en Pensamiento vol. 49 (1993), núm. 193, págs. 35-61.

Rodríguez Valls, F. "Libertad y determinismo en la Ética de Spinoza”, en Ortega, F. J. y J. Tejada (eds.) Libertades. Huelva. Hergué editorial, 2005. Págs. 165-204.

Vinti, C. Spinoza. Conoscenza come liberatione. Roma. Studium, 1984. 